\title{
Automated segmentation of optic nerve head for the topological assessment
}

\author{
M. W L Ko, C. K S Leung, T. Y P Yuen
}

- School of Engineering

\section{Abstract}

An automated method is proposed to detect the optic nerve head $(\mathrm{ONH})$ surface profile for the three-dimensional reconstruction of the $\mathrm{ONH}$ surface topology and for the determination of the optic nerve head surface depth (ONHSD) and optic nerve head surface volume (ONHSV). The proposed automated method was evaluated in 15 optic disc center B-scans and was compared to the manual detection method. The results showed a good agreement between the measurement of ONHSD $(0.7 \% \pm 1.0 \%)$ and ONHSV $(-1.4 \% \pm 3.2 \%)$ using manual and automated $\mathrm{ONH}$ profile, respectively.

Original language

Title of host publication

Publisher

ISBN (Electronic)

State

Event

Other

Country

City

Period
English

2016 Global Medical Engineering Physics Exchanges/Pan American Health Care Exchanges, GMEPE/PAHCE 2016

Institute of Electrical and Electronics Engineers Inc.

9781509024858

Published - Jul 52016

2016 Global Medical Engineering Physics Exchanges/Pan American Health Care Exchanges, GMEPE/PAHCE 2016 - Madrid, Spain

2016 Global Medical Engineering Physics Exchanges/Pan

American Health Care Exchanges, GMEPE/PAHCE 2016

Spain

Madrid

$4 / 4 / 16 \rightarrow 4 / 9 / 16$

Ko, M. W. L., Leung, C. K. S., \& Yuen, T. Y. P. (2016). Automated segmentation of optic nerve head for the topological assessment. In 2016 Global Medical Engineering Physics Exchanges/Pan American Health Care Exchanges, GMEPE/PAHCE 2016. [7504611] Institute of Electrical and Electronics Engineers Inc.. DOI: 10.1109/GMEPE-PAHCE.2016.7504611 